\title{
THE FEASIBILITY OF CRANIOFACIAL SKELETAL FIXATION USING CYANOACRYLATE GLUE BASED ON CLINICAL EXPERIENCE, AT A GOVERNMENTAL HOSPITAL, ALEXANDRIA, EGYPT
}

\author{
Ahmed M.A. Habib * and Mohamed M. Fata**
}

\begin{abstract}
Objective: The purpose of this study was to present experience using cyanoacrylate tissue glue in fixation of onlay bone grafts used in different craniofacial reconstruction situations

Design: Prospective analysis of patients with craniofacial defects including nasofrontal encephalocele and post traumatic craniofacial fractures repaired by onlay bone grafts.

Setting: Institutional center

Patients/Participants: A total of 27 patients presented with nasofrontal encephalocele (5) and post traumatic craniofacial fractures (22).

Interventions: Reconstruction of nasofrontal defects using onlay bone grafts fixed by cyanoacrylate tissue glue

Outcome Measures: Patients had repair using bone grafts fixed by cyanoacrylate tissue glue between 2010 and 2013. Patients' photographs, and clinical records, were collected. The technique of defect reconstruction and method of bone grafts securing it in its position is described in this study.
\end{abstract}

Results: Patients were followed up over a mean period of 12.6 months to clinically check the stability of the reconstruction, and the contour of the cranium. All patients showed uneventful healing without complications.

Conclusions: This technique offered a secure method of onlay bone fixation during reconstruction. Further researches are needed to show this technique advantages and drawbacks.

KEY WORDS: Cyanoacrylate, bone graft, craniofacial, glue.

* Department of Maxillofacial and Plastic Surgery, Faculty of Dentistry, Alexandria University, Egypt.

** Corresponding author: Ahmed Habib; Lecturer of Maxillofacial and Plastic Surgery, Faculty of Dentistry, Alexandria University, Egypt. 


\section{INTRODUCTION}

Fixation of bone grafts used for craniofacial reconstruction is an essential step for integration in the host bed. The commonly used method is fixation with titanium miniplates and screws that provides tridimensional positioning and stability of the graft (Saska et al., 2009).

Alkyl-2-cyanoacrylates were discovered in 1949 by Ardis (1949), but it was not used until 1959 that its adhesive properties were described by Coover et al. (1959) and used for industrial purposes.

During the last 50 years, Cyanoacrylate preparations have been used in different surgical applications. They were initially used as surgical glue (Choi et al., 2004; Landegren et al., 2006). They polymerise rapidly within seconds following contact with proteinaceous surfaces to form strong and flexible bonds (Choi et al., 2004). This chemical property makes them extensively used in different surgical applications; they have been used for wound closure (Penoff, 1999), haemostasis of gastrointestinal bleeding (Chang et al., 2010), obliteration of tracheo-oesophageal (Tzifa et al., 2006), bronchobiliary (Goldman et al., 2007), and cerebrospinal fistulae (Hida et al., 2006), skin graft fixation (Adler et al., 2007), and other surgical indications (Hallock, 2001).

The use of cyanoacrylates in maxillofacial surgery includes cleft lip and palate repair, oral dressing, skin graft fixation, nasal splinting, immobilisation of traumatised teeth, management of chyle leak during neck dissection and wound closure (Hallock, 2001; Habib et al., 2013).

Fixation of bone grafts requires a method that ensures adequate fixation without interfering with the incorporation of the graft into the host bed. Some authors report that bone fragments fixed with cyanoacrylate-based adhesives have better success, superior stability and better conditions for new bone formation compared with screw fixation (Ahn et al., 1997).
Over the last decades, many clinical trials were attempted to fix maxillofacial bone grafts using cyanoacrylate based adhesives with encouraging results showing that bone fragments fixed with cyanoacrylate-based adhesives have better success, superior stability and better conditions for new bone formation compared with screw fixation (Mehta et al., 1987; Amarante et al., 1995; Ahn et al., 1997).

We present our experience with the use of cyanoacrylate medical preparation for fixation of autogenous onlay bone grafts used in reconstruction of craniofacial defects due to trauma or congenital nasofrontal encephalocele.

\section{MATERIALS AND METHODS}

Between 2010 and 2013, Histoacryl ${ }^{\circledR}$ Tissue Adhesive (B.Braun, Aesculap, Germany) was used for fixation of onlay bone grafts used in craniofacial reconstruction in 27 patients.

Most of reconstructions in our series (22 out of 27) were post traumatic; the other five patients had congenital nasofrontal encephalocele.

Prior to application of cyanoacrylate, the tissue surfaces should be clean and dry as much as possible. Protection of the surrounding tissues from accidental contact with cyanoacrylate can be done by coverage them by gauze, or chloramphenicol $1 \%$ ointment. Careful application drop by drop is better than rapid massive application. After its application, tissues are immobilized for 30 seconds to have the polymerisation reaction complete.

The bone grafts were replaced in position in close contact to the perimeter of the bony defects (Figure 1). The fragments were fixed with butyl-2cyanoacrylate (Histoacryl, R. Braun, Melsungen, Germany). The adhesive was applied on the contact area of the bone grafts and the grafts were adhered to the bone defect perimeter by applying mild pressure for 30 seconds (Figures 1 b, c). After making sure that the bone grafts were securely fixed in place, 

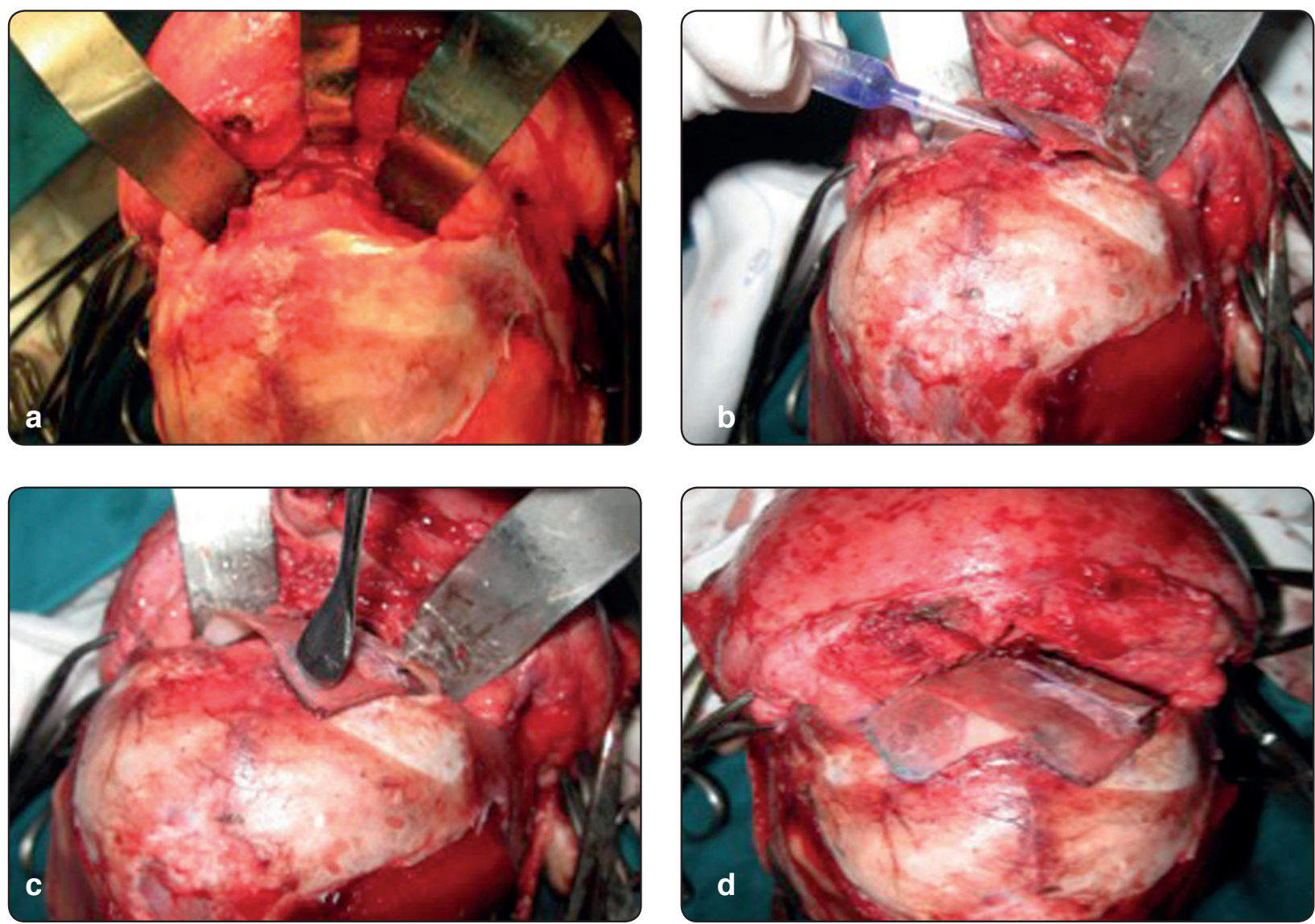

FIG. 1 A 6 month old patient presented with nasofrontal encephalocele a: the fronto-orbital bony defect after excision of the encephalocele. b: reconstruction of the bony defect using calvarial bone grafts fixed in place by cyanoacrylate glue. c: pressure is applied for 30 seconds after application of cyanoacrylate glue. d: all bony grafts are held together and adapted well in place by cyanoacrylate glue only.

closure in layers was attempted with insertion of suction drains (Figure 1d).

The Helsinki Declaration guidelines have been followed in this investigation.

\section{RESULTS}

\section{Clinical Analysis}

All operated patients healed uneventfully, and no wound complications or evidence of adverse inflammatory reactions occurred. Clinical assessment showed no displacement of the onlay bone grafts, and the contour of the cranium was restored and maintained.

\section{Radiographic Assessment}

Since no postoperative movement of the bone grafts was detected on postoperative clinical follow up; and in order to minimise the risk of imaging radiation especially in infantile encephalocele, we did not ask for postoperative radiological investigations.

\section{DISCUSSION}

Reconstruction of craniofacial bony defects by onlay bone grafts is a very common procedure by many surgeons. The success rates depend on many factors such as are position, origin, microarchitecture, load and strain, orientation, presence of periosteum, 
host bed, revascularization rate and fixation method (Tong and Buchman, 2000).

Among these factors, rigid fixation of the grafts is considered the main survival success parameter. The variable volume loss caused by resorption is closely related to fixation. Rigid internal fixation with screws enhances the survival of onlay grafts compared with wires or no fixation, especially in mobile areas (Phillips and Rahn, 1988; Shermak et al., 1998b; Lin et al., 1990; Amarante et al., 1995).

The use of metal plates and screws is considered the corner stone in rigid fixation of the craniofacial skeleton; they provide stable three- dimensional positioning of bone fragments. With more research and improvements of manufacture; the size of the metal plates and screws has been made smaller, resulting in less foreign material implanted during surgery (Suuronen 1991; Iizuka and Lindqvist, 1992).

Although many authors reported the unnecessary removal of these small miniplates and screws, others claimed the risk of migration, carcinogenic potential, corrosion, and other side effects of metallic implants which necessitate their removal after bony healing (Suuronen 1991; Iizuka and Lindqvist, 1992).

The use of biodegradable materials for craniofacial bone fixation is being developed to overcome the problems associated with the use of metallic plates and screws. The ideal material should provide rigid fixation enough to maintain the bone fragments in place without affecting bone healing. It should not cause any systemic or local reaction, nor be allergenic, immunogenic, mutagenic, or teratogenic and should disintegrate totally after bony healing (Böstman, 1991; Suuronen et al., 1991; Suuronen, 1993).

Amarante et al. (1995) demonstrated effective stability and healing of osteotomized bone fragments in an animal model similar to that used in this study using butyl-2-cyanoacrylate adhesive without additional internal fixation.
Saska et al. (2009) compared fixation of autogenous bone grafts with ethyl-cyanoacrylate glue, a commercial adhesive not designed for surgical use, with that done with titanium screws in the calvaria of rabbits. In their series, fixation with ethyl-cyanoacrylate adhesive promoted a significantly greater area of bone graft than the area of the graft fixed with the titanium screw, independent of the time period. Grafts fixed with adhesive maintained their original area more than those fixed with screws. The adhesive promoted stability of the graft.

Combining the favourable outcomes of cyanoacrylate adhesives usage reported by others in craniomaxillofacial surgery, we hypothesized that we could achieve sufficient rigid fixation to allow bone healing equivalent to that observed with metal plate and screw fixation. We used cyanoacrylate as surgical glue in fixation of onlay bone grafts in 27 patients with craniofacial bony defects with satisfactory results. Although many cyanoacrylates are available, we chose to use Histoacryl ${ }^{\circledR}$, a butyl2-cyanoacrylate, because it is already approved for use in humans in many countries around the world. It proved to be a reliable tissue adhesive in every indication it was used for without any clinical irritation to the tissues (Ahn et al., 1997; Shermak et al., 1998a).

Cyanoacrylate adhesive has many potential advantages over metallic fixation systems, including low cost, ease of use, rapid application, ability to be resorbed, and easy modification of fixation intraoperatively. Cyanoacrylates function well in moist environments; thus the surfaces to be bonded do not have to be totally dry (Brauer et al., 1979). Cyanoacrylates are reported to have certain bacteriostatic and bactericidal effects that may be valuable characteristics when dealing with tissues that have suffered vascular insult and possibly open trauma (Awe et al., 1963; Eiferman and Snyder, 1983). 
The main potential problem of cyanoacrylate is the heat production during polymerisation. We tried to avoid this by careful drop by drop application with protection of the surrounding tissues with gauze and ointment. Also capacious normal saline solution was always ready in case of accidental exposure. The amount of heat, which is produced by drilling for screws, when compared to that produced by glue polymerisation, is not known to the authors (Blythe et al, 2011).

Low cytotoxic effect is another potential problem. Ciapetti et al. (1994a; b) have reported on the cytotoxicity of four different cyanoacrylates on cultured cells, however they concluded that those with butyl side chains were best tolerated by the cells. Nonetheless, Vanholder et al. (1993) reported on a randomized study comparing Mediglue, an ethyl-[alpha]-cyanoacrylate, with skin suturing and found no toxic reactions and that the adhesive did not retard wound healing. Preliminary data on fixing cranial bones with cyanoacrylate have not demonstrated toxicity to neural tissues either (Shermak et al., 1998a).

However, in the ever increasing number of clinical publications that are being published on its use in surgery, these potential complications do not seem to be problematic (Buckley and Beckman, 2010; Landegren et al., 2010; Blythe et al., 2011; Clarke, 2011; Habib et al., 2013).

\section{CONCLUSIONS}

Despite the limited number of patients, the data from this study demonstrate that fixation of craniofacial onlay bone grafts by surgical glue was as effective as metal plates and screws for providing stable positioning of bone grafts in the upper facial skeleton.

Although metal plate and screw fixation will remain an essential part of the armamentarium for craniofacial surgery and the introduction of new biodegradable devices will provide a useful adjunct, the use of an adhesive alone also may have clear indications.
Further clinical trials are necessary to confirm our results and to determine the real effectiveness of this technique.

\section{REFERENCES}

1. Adler N, Nachumovsky S, Meshulam-Derazon S, Ad-El D. Skin graft fixation with cyanoacrylate tissue adhesive in burn patients. Burns.2007;33:803.

2. Ahn DK, Sims CD, Randolph MA, O'Connor D, Butler PEM, Amarante MJT, Yaremchuk MJ. Craniofacial skeletal fixation using biodegradable plates and cyanoacrylate glue. Plast Reconst Surg.1997;99:1508-1517.

3. Amarante MTJ, Constantinescu MA, O’Connor D, Yaremchuk MJ. Cyanoacrylate fixation of the craniofacial skeleton an experimental study. Plast Reconst Surg. 1995; 95:639-646.

4. Ardis AE. U.S. Patents No. 2467926 and 2467927,1949

5. Awe WC, Roberts W, Braunwald NS. Rapidly polymerizing adhesive as a hemostatic agent. Study of tissue response and bacteriological properties. Surgery. 1963;54:322-328.

6. Blythe JN, Habib A, Gulati A, Brennan PA. Use of N-butyl-2-cyanoacrylate tissue glue in thoracic duct injury during neck dissection surgery. Br J Oral Maxillofac Surg. 2011;49:486-487

7. Böstman OM. Absorbable implants for the fixation of fractures. J Bone Joint Surg Am. 1991; 73:148-153.

8. Brauer GM, Kumpula JW, Termini DJ, Davidson KM. Durability of the bond between bone and various 2-cyanoacrylates in an aqueous environment. J Biomed Mater Res. 1979;13:593-606,

9. Buckley MJ, Beckman EJ. Adhesive use in oral and maxillofacial surgery. Oral Maxillofac Surg Clin North Am. 2010; 22:195-199.

10. Chang CJ, Hou MC, Lin HC, Lee HS, Liao WC, Su $\mathrm{CW}$, Lee SD. The safety and probable therapeutic effect of routine use of antibiotics and simultaneously treating bleeding gastric varices by using endoscopic cyanoacrylate injection and concomitant esophageal varices with banding ligation: a pilot study. Gastrointest Endosc. 2010; 71:1141-1149.

11. Choi BH, Kim BY, Huh JY, Lee SH, Zhu SJ, Jung JH, Cho BP. Microneural anastomosis using cyanoacrylate adhesives. Int J Oral Maxillofac Surg. 2004;33:777-780. 
12. Ciapetti G, Stea S, Cenni E, Sudanese A, Marraro D, Toni A, Pizzoferrato A. Cytotoxicity testing of cyanoacrylates using direct contact assay on cell cultures. Biomaterials. 1994a;15: 63-67.

13. Ciapetti G, Stea S, Cenni E, Sudanese A, Marraro D, Toni A, Pizzoferrato A. Toxicity of cyanoacrylates in vitro using extract dilution assay on cell cultures. Biomaterials. 1994b;15: 92-96.

14. Clarke TF. Cyanoacrylate glue burn in a child - lessons to be learned. J Plast Reconstr Aesthet Surg. 2011; 64:e170-173.

15. Coover HW, Joyner FB, Shearer NH, Wicker TH. Chemistry and performance of cyanoacrylate adhesives. J Soc Plast Eng. 1959;15:413-417.

16. Eiferman RA, Snyder JW. Antibacterial effect of cyanoacrylate glue. Arch Ophthalmol. 1983;101:958-960.

17. Goldman SY, Greben CR, Setton A, McKinley MJ, Axelrod DJ, Charles HW, Gandras EJ. Bronchobiliary Fistula Successfully Treated with n-Butyl Cyanoacrylate via a Bronchial Approach. J Vasc Interv Radiol. 2007; 18:151-155.

18. Habib A, Mehanna A, Medra A. Cyanoacrylate: a handy tissue glue in maxillofacial surgery: our experience in alexandria, egypt. J Maxillofac Oral Surg. 2013;12:243-247.

19. Hallock GG. Expanded Applications for Octyl-2-cyanoacrylate as a Tissue Adhesive. Ann Plast Surg. 2001;46:185189.

20. Hida K, Yamaguchi S, Seki T, Yano S, Akino M, Terasaka S, Uchida T, Iwasaki Y. Nonsuture dural repair using polyglycolic acid mesh and fibrin glue: clinical application to spinal surgery. Surg Neurol. 2006;65:136-142.

21. Iizuka T, Lindqvist C. Rigid internal fixation of mandibular fractures: An analysis of 270 fractures treated using the AO/ASIF method. Int J Oral Maxillofac Surg. 1992; 21:65-69.

22. Landegren T, Risling M, Brage A, Persson JK. Long-term results of peripheral nerve repair: a comparison of nerve anastomosis with ethyl-cyanoacrylate and epineural sutures. Scand J Plast Reconstr Surg Hand Surg. 2006;40:65-72.

23. Landegren T, Risling M, Persson JK, Sondén A. Cyanoacrylate in nerve repair: transient cytotoxic effect. Int J Oral Maxillofac Surg. 2010;39: 705-712.

24. Lin KY, Bartlett SP, Yaremchuk MD, Fallon M, Grossman RF, Whitaker LA. The effect of rigid fixation on the survival of onlay bone graft. An experimental study. Plast Reconst Surg. 1990;86:449-456.
25. Mehta MJ, Shah KH, Bhatt RG. Osteosynthesis of mandibular fractures with n-butyl cyanoacrylate: a pilot study. J Oral Maxillofac Surg. 1987;45:393-396.

26. Penoff J. Skin closures using cyanoacrylate tissue adhesives. Plastic Surgery Educational Foundation DATA Committee. Device and Technique Assessment. Plast Reconstr Surg. 1999;103:730-731

27. Phillips JH, Rahn BA. Fixation effects on membranous and endochondral onlay bone-graft resorption. Plast Reconst Surg. 1988;82:872-877.

28. Saska S, Hochuli-Vieira E, Minarelli-Gaspar AM, Gabrielli MF, Capela MV, Gabrielli MA. Fixation of autogenous bone grafts with ethyl-cyanoacrylate glue or titanium screws in the calvaria of rabbits. Int $\mathbf{J}$ Oral Maxillofac Surg. 2009;38:180-186.

29. Shermak MA, Wong L, Inoue N, Crain BJ, Im MJ, Chao EY, Manson PN. Fixation of the craniofacial skeleton with butyl-2-cyanoacrylate and its effects on histotoxicity and healing. Plast Reconstr Surg. 1998a;102:309-318.

30. Shermak MA, Wong L, Inoue N, Crain BJ, Im MJ, Chao EYS, Manson PN. Butyl-2 cyanoacrylate fixation of mandibular osteotomies. Plast Reconst Surg. 1998b;102:319324.

31. Suuronen R, Laine P, Sarkiala E, Pohjonen T, Lindqvist C. Sagittal split osteotomy fixed with biodegradable, selfreinforced poly-L-lactide screws: A pilot study in sheep. Int J Oral Maxillofac Surg. 1991;21:303-308.

32. Suuronen R. Comparison of absorbable self-reinforced poly-L-lactide screws and metallic screws in the fixation of mandibular condyle osteotomies. J Oral Maxillofac Surg. 1991;49: 989-995.

33. Suuronen R. Biodegradable fracture-fixation devices in maxillofacial surgery. Int J Oral Maxillofac Surg. 1993;22: 50-57.

34. Tong L, Buchman SR. Facial bone grafts: contemporary science and thought. J Cranio-maxillo Trauma. 2000;6:3141.

35. Tzifa KT, Maxwell EL, Chait P, James AL, Forte V, Ein $\mathrm{SH}$, Friedburg J. Endoscopic treatment of congenital HType and recurrent tracheoesophageal fistula with electrocautery and histoacryl glue. Int J Pediatr Otorhinolaryngol. 2006;70:925-930.

36. Vanholder R, Misotten A, Roels H, Matton G. Cyanoacrylate tissue adhesive for closing skin wounds: A double blind randomized comparison with sutures. Biomaterials. 1993;14:737-742. 